\title{
The Evolution of Microstructure and Mechanical Properties of Al-Mn-Fe-Si Alloys During Isothermal Annealing
}

\begin{abstract}
M. Poková*, M. Zimina, M. Cieslar
Charles University in Prague, Faculty of Mathematics and Physics, Department of Physics of Materials, Ke Karlovu 5, Prague 2, 121 16, Czech Republic

Recrystallization during isothermal annealing is studied in a twin-roll cast $\mathrm{Al}-\mathrm{Mn}-\mathrm{Fe}-\mathrm{Si}$ alloy with $\mathrm{Zr}$ addition. $\mathrm{Al}_{3} \mathrm{Zr}$ precipitates, which are known to improve the recrystallization resistance by exerting the Zener drag on migrating grain boundaries, form during heat treatment at $450{ }^{\circ} \mathrm{C}$. Materials with and without $\mathrm{Al}_{3} \mathrm{Zr}$ precipitates are subjected to 4 passes of equal channel angular pressing at room temperature and a submicrometric grain size is achieved. In the course of isothermal annealing materials recrystallize at $400{ }^{\circ} \mathrm{C}, 425^{\circ} \mathrm{C}$ and $450{ }^{\circ} \mathrm{C}$. The time required for recrystallization follows an Arrhenius equation. Recrystallization kinetics is similar independently of the presence of $\mathrm{Al}_{3} \mathrm{Zr}$ precipitates. Precipitation of $\alpha-\mathrm{Al}(\mathrm{Mn}, \mathrm{Fe}) \mathrm{Si}$ particles is thought to increase the recrystallization resistance in the material without $\mathrm{Al}_{3} \mathrm{Zr}$.
\end{abstract}

DOI: 10.12693 /APhysPolA.128.746

PACS: 68.37.Lp, 68.37.Hk, 81.30.Mh, 81.40.Ef, 61.72.Mm

\section{Introduction}

Equal channel angular pressing (ECAP) is a commonly used method of severe plastic deformation (SPD). The main objective of SPD is grain size reduction and the associated strength increase [1,2]. During ECAP the billet of the material is pressed through a die which consists of two channels of equal cross-section intersecting at an angle $\Phi$, usually $90^{\circ}[3]$. The main advantage of this technique is the possibility of repeating the pressing several times, inducing a required level of strain into the material and producing relatively large ultra-fine grained bulk materials.

The method of twin-roll casting (TRC) of aluminium alloys is an alternative to conventional casting techniques. It provides a high solidification rate and produces highly supersaturated materials with enhanced mechanical properties. During annealing small dispersoids precipitate from the supersaturated aluminium matrix [46]. Precipitation in non-heat treatable Al-Mn-based alloys occurs mainly heterogeneously on dislocations, subgrain and grain boundaries [7]. Recently, the microstructure evolution in TRC alloys was intensively studied (e.g. [8-10]). However, nearly no results are available on SPD processed TRC alloys, although the superposition of higher supersaturation with intensive plastic deformation could guarantee a new class of high-strength materials.

During the high temperature treatment recrystallization and grain growth can take place. The methods how to preserve the submicrometric size of the grains are under intensive research (e.g. [11]). By adding small amounts of zirconium into aluminum alloys metastable coherent dispersoids $\mathrm{Al}_{3} \mathrm{Zr}$ with cubic $L 1_{2}$ structure can be formed. They can retard the motion of lattice

${ }^{*}$ corresponding author; e-mail: pokova@karlov.mff.cuni.cz dislocations and grain boundaries and contribute to a better stability of the microstructure at elevated temperatures $[12,13]$. These particles can be formed during isothermal annealing at $450{ }^{\circ} \mathrm{C}$ preceded by a slow temperature increase $[14,15]$.

The aim of the present study is to evaluate the influence of $\mathrm{Al}_{3} \mathrm{Zr}$ precipitates on the recrystallization kinetics in TRC ultra-fine grained $\mathrm{Al}-\mathrm{Mn}-\mathrm{Fe}-\mathrm{Si}$ alloy after ECAP during isothermal annealing at three different temperatures.

\section{Experimental}

In the present work, aluminium alloy from AA3003 series (1.02 wt.\% Mn, 0.23 wt.\% Fe and 0.58 wt.\% Si) modified by an addition of $0.16 \mathrm{wt} . \% \mathrm{Zr}$ was studied. The alloy was twin-roll cast in industrial conditions and subsequently annealed in an air furnace with a heating rate of $0.5 \mathrm{~K} / \mathrm{min}$ to $450^{\circ} \mathrm{C}$ and held at $450{ }^{\circ} \mathrm{C}$ for $8 \mathrm{~h}$. This treatment led to the formation of a fine dispersion of $\mathrm{Al}_{3} \mathrm{Zr}$ precipitates [16]. Both, the as-cast material and the annealed one were subjected to four ECAP passes at room temperature, employing the pressing speed $10 \mathrm{~mm} / \mathrm{min}$ and the route $\mathrm{B}_{c}$, where the sample is rotated by $90^{\circ}$ after each pass [17].

Previous investigation [18] showed that pre-annealing at $450{ }^{\circ} \mathrm{C}$ does not influence the recrystallization temperature during isochronal annealing - both pre-annealed and non-annealed materials recrystallize between $400{ }^{\circ} \mathrm{C}$ and $450^{\circ} \mathrm{C}$. Isothermal annealing at $400^{\circ} \mathrm{C}, 425^{\circ} \mathrm{C}$, and $450^{\circ} \mathrm{C}$ was applied in order to describe the kinetics of recrystallization and determine the role of pre-annealing. Mechanical properties were investigated by the Vickers microhardness (HV) measurement with a $100 \mathrm{~g}$ load and the microstructure evolution was observed, using a transmission electron microscope (TEM) JEOL JEM $2000 \mathrm{FX}$ and a scanning electron microscope (SEM) FEI Quanta FEG 200 equipped with electron backscatter diffraction (EBSD). 


\section{Results}

The evolution of the Vickers microhardness during isothermal annealing at $400^{\circ} \mathrm{C}, 425^{\circ} \mathrm{C}$, and $450{ }^{\circ} \mathrm{C}$ from 0.5 to $32 \mathrm{~h}$ is shown in Fig. 1. After a short annealing time at elevated temperature the microhardness drops significantly from initial values of $100 \mathrm{HV} 0.1$ for the non-annealed and $90 \mathrm{HV} 0.1$ for the pre-annealed material, respectively. At the highest annealing temperature $450{ }^{\circ} \mathrm{C}$ the microhardness drop is very steep. After $30 \mathrm{~min}$ the average microhardness reaches $50 \mathrm{HV} 0.1$ and both materials preserve this value during further exposure to $450^{\circ} \mathrm{C}$.

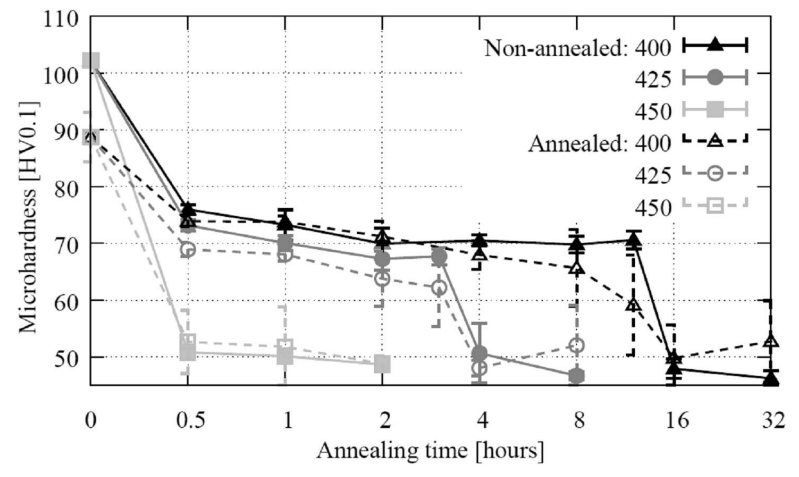

Fig. 1. The evolution of Vickers microhardness during isothermal annealing at 400,425 and $450{ }^{\circ} \mathrm{C}$ for both pre-annealed and non-annealed material.

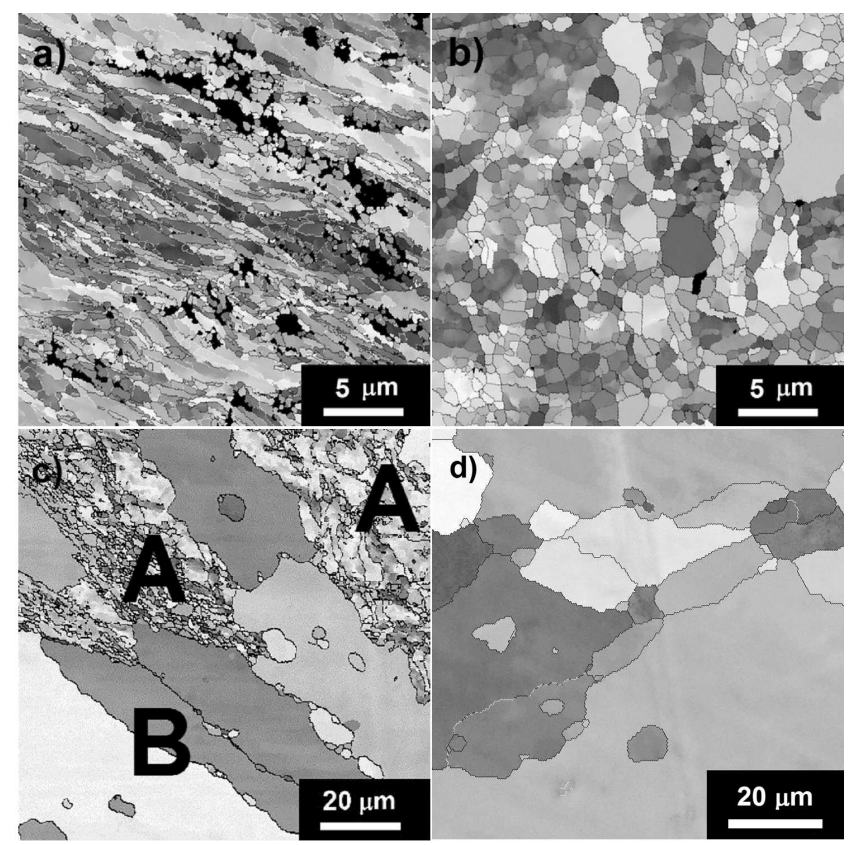

Fig. 2. EBSD orientation map of grains in the material non-annealed prior to ECAP during annealing at $425^{\circ} \mathrm{C}$. High angle grain boundaries are represented by dark lines. a) just after ECAP, b) 1 hour, c) 3 hours (A deformed, B - recrystallized parts), d) 4 hours.
In materials annealed at $400{ }^{\circ} \mathrm{C}$ and $425^{\circ} \mathrm{C}$ for $0.5 \mathrm{~h}$ the decrease of microhardness to values around 70 and 75 HV0.1 is followed by a plateau. Nevertheless, after longer annealing times also at these temperatures the microhardness drops to a final value of about 50 HV0.1. A significantly shorter time between 3 and $4 \mathrm{~h}$ is necessary at $425^{\circ} \mathrm{C}$, while at $400^{\circ} \mathrm{C}$ the main microhardness drop from 70 to 50 HV0.1 takes place between 12 and $16 \mathrm{~h}$ of annealing.

Observations in SEM by EBSD enabled examination of the grain structure. After four ECAP passes materials contain sub-micrometric grains which are separated by high angle grain boundaries (Fig. 2a). During the initial stages of annealing at elevated temperature the average grain size increases slightly from $0.4 \mu \mathrm{m}$ to approximately $1 \mu \mathrm{m}$ (Fig. 2b). Due to further annealing these grains are stable to the point, where grains of the size $20-100 \mu \mathrm{m}$ appear. These new grains are separated by high angle grain boundaries.

After a short period at $450{ }^{\circ} \mathrm{C}$ part of the specimen contains new, recrystallized grains with an average size of $50 \mu \mathrm{m}$. The recrystallized fraction is higher in the preannealed material. After $1 \mathrm{~h}$ at $450^{\circ} \mathrm{C}$ the microstructure is fully recrystallized in both materials (pre-annealed and non-annealed prior to ECAP). After $3 \mathrm{~h}$ at $425^{\circ} \mathrm{C}$ half of the microstructure consists of micrometric grains or subgrains, the second half is built up of new grains with no subgrain substructure (Fig. 2c - areas A and B). Further annealing to $4 \mathrm{~h}$ results in a full transformation to a coarse-grained structure. However, small grains with a diameter around $10 \mu \mathrm{m}$ inside large ones are still observed (Fig. 2d). During heat treatment at $400^{\circ} \mathrm{C}$, a limited number of recrystallization nuclei is observed in the preannealed material even after $4 \mathrm{~h}$. Full recrystallization takes place after $16 \mathrm{~h}$ in both types of materials; however, the first traces of recrystallization in the non-annealed material are not observed until $8 \mathrm{~h}$ of annealing.

TEM observation shows that the microstructure after ECAP processing consists of sub-micrometric grains with a high density of dislocations (Fig. 3a). After a short period at $400^{\circ} \mathrm{C}$ the dislocation substructure is fully recovered and high angle grain boundaries dominate (Fig. 3b). Precipitation of the $\alpha-\mathrm{Al}(\mathrm{Mn}, \mathrm{Fe}) \mathrm{Si}$ phase is another effect of isothermal annealing at all temperatures. Examinations in TEM show that a high density of these particles is present in both materials after heat treatment. In the material, which was not annealed prior to ECAP, all precipitates form during the post-ECAP heating. They are located mainly on grain boundaries. In the pre-annealed specimen, besides the precipitates, which were present in the material before ECAP, new ones form, while a significant coarsening of the original ones occurs.

\section{Discussion}

During isothermal annealing at elevated temperatures the sub-micrometric grains are replaced by new grains with a size comparable to the state before plastic deformation by ECAP. However, the grain distribution is 

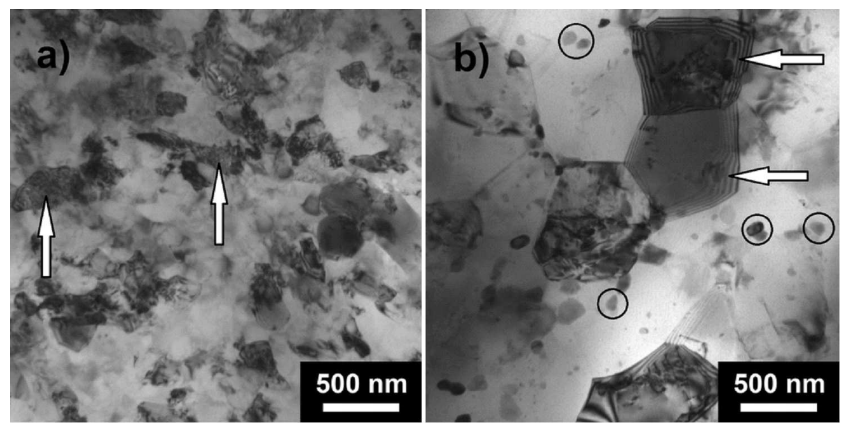

Fig. 3. (a) TEM image of the non-annealed alloy after 4 ECAP passes containing a high dislocation density (arrows) and (b) after 1 hour of annealing at $400{ }^{\circ} \mathrm{C}$ with $\alpha-\mathrm{Al}(\mathrm{Mn}, \mathrm{Fe}) \mathrm{Si}$ precipitates (circles) and high angle grain boundaries (arrows).

inhomogeneous and some of the grains retain smaller size around $10 \mu \mathrm{m}$. The time necessary for full recrystallization highly depends on the annealing temperature: at $400{ }^{\circ} \mathrm{C}$ it takes $16 \mathrm{~h}$ for full recrystallization, at $425^{\circ} \mathrm{C}$ only $4 \mathrm{~h}$. At the highest applied temperature $450^{\circ} \mathrm{C}$ the recrystallization is very fast, a high fraction of the matrix recrystallizes already during $10 \mathrm{~min}$ of exposure to the elevated temperature.

The time corresponding to $50 \%$ recrystallization $t_{R X}$ is related to the annealing temperature $T$ with an activation energy for recrystallization $Q_{R X}$ in an Arrheniustype representation

$$
t_{R X}=\tau_{0} \exp \left(\frac{Q_{R X}}{R T}\right),
$$

where $\tau_{0}$ is a constant and $R$ is the universal gas constant [19]. This may be represented as a linear fit of $\ln \left(t_{R X}\right)$ against $1 / T$ (Fig. 4). The activation energy $Q_{R X}$ is known to be strongly affected by the state of the solid solution and precipitation and in cold-rolled aluminium alloys it varies from 200 to $500 \mathrm{~kJ} / \mathrm{mol}[20,21]$. The value estimated from data in the present study $\left(Q_{R X}=(275 \pm 30) \mathrm{kJ} / \mathrm{mol}\right)$ agrees well with the literature data.

The time required for recrystallization at all selected temperatures does not depend on the alloy pretreatment. This means that the initial annealing at $450^{\circ} \mathrm{C}$, which was conducted in order to enhance thermal stability of the alloy at high temperatures, does not meet the requirement. Moreover, the first recrystallized grains emerge at a given temperature in the pre-annealed material after a shorter annealing time than in the nonannealed one. This may be caused by the depletion of the matrix from $\mathrm{Mn}$ and also by a higher density of $\alpha$ $\mathrm{Al}(\mathrm{Mn}, \mathrm{Fe}) \mathrm{Si}$ phase particles, which are present in the matrix prior to isothermal annealing. Such particles can promote recrystallization serving as preferential nucleation sites for recrystallization through the particle stimulated nucleation. Both effects thus can override the beneficial influence of $\mathrm{Al}_{3} \mathrm{Zr}$ precipitates. Precipitation taking place concurrently with recrystallization is known to en-

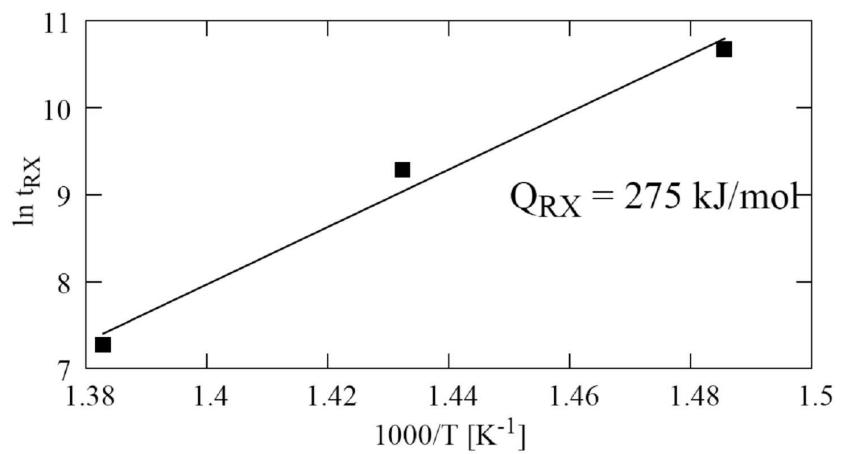

Fig. 4. Linear relation between the logarithm of time necessary to $50 \%$ recrystallization $t_{R X}$ to the reciprocal of the annealing temperature $T$, used for the calculation of activation energy $Q_{R X}$.

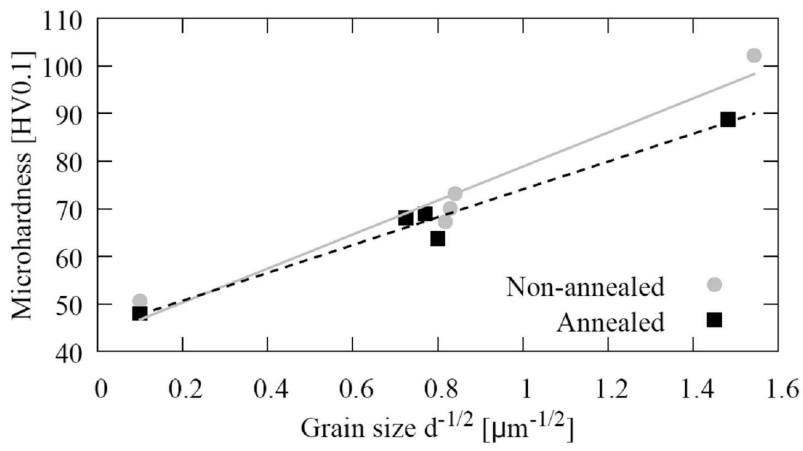

Fig. 5. The relation of Vickers microhardness and average grain size $d$ during isochronal annealing at $425^{\circ} \mathrm{C}$, fitted to a Hall-Petch relation (Eq. 2).

hance recrystallization resistance $[5,22]$. This is the case of the non-annealed material, where new $\alpha-\mathrm{Al}(\mathrm{Mn}, \mathrm{Fe}) \mathrm{Si}$ particles form during annealing and enhance the recrystallization resistance in the same extent as $\mathrm{Al}_{3} \mathrm{Zr}$ precipitates in the pre-annealed alloy.

The increase of average grain size during annealing is connected with microhardness via the Hall-Petch relation - the microhardness HV drops as the reciprocal of the square root of the average grain size $d$ :

$$
H V=H_{0}+\frac{K_{H}}{\sqrt{d}},
$$

where $H_{0}$ and $K_{H}$ are coefficients typical of each material [23]. Following the Hall-Petch relationship (Eq. (2)) the microhardness and grain size evolution during isothermal annealing at $425^{\circ} \mathrm{C}$ follow a linear dependence of microhardness on inverse square root of the average grain size (Fig. 5). Fitted parameters from Eq. (2) are $K_{H}=(43 \pm 4) \mathrm{HV} 0.1 / \sqrt{\mu \mathrm{m}}$ and $H_{0}=(36 \pm 5) \mathrm{HV} 0.1$ for the alloy non-annealed prior to ECAP and $K_{H}=$ $(45 \pm 6) \mathrm{HV} 0.1 / \sqrt{\mu \mathrm{m}}$ and $H_{0}=(29 \pm 4) \mathrm{HV} 0.1$ for the preannealed one. These values are comparable with the values obtained generally on severely deformed aluminium alloys $[23,24]$. 


\section{Conclusion}

Twin-roll cast AA3003 aluminium alloy modified by a small amount of zirconium was studied. Ultra-fine grained structure was formed by ECAP. Isothermal annealing at 400,425 , and $450^{\circ} \mathrm{C}$ leads to recovery of dislocation substructure, recrystallization of deformed structure and to precipitation of $\alpha-\mathrm{Al}(\mathrm{Mn}, \mathrm{Fe}) \mathrm{Si}$ particles. The time necessary for recrystallization decreases with increase of annealing temperature, independently of the heat pre-treatment. In the pre-annealed material the recrystallization resistance is attributed to $\mathrm{Al}_{3} \mathrm{Zr}$ precipitates, in non-annealed material to the concurrent precipitation of the $\alpha-\mathrm{Al}(\mathrm{Mn}, \mathrm{Fe}) \mathrm{Si}$ phase.

\section{Acknowledgments}

The financial supports of grants GAČR P107-12-0921, GAUK 1428213 and SVV-2014-260091 are gratefully acknowledged.

\section{References}

[1] M. Cabibbo, Mater. Sci. Eng. A 560, 413 (2013).

[2] D. Jiang, J. Ning, J. Sun, Z. Hu, Y. Hou, Trans. Nonferrous Met. Soc. China 18, 248 (2008).

[3] Z. Horita, T. Fujinami, M. Nemoto, T. G. Langdon, J. Mater. Process. Tech. 117, 288 (2001).

[4] M. Karlík, T. Mánik, H. Lauschmannkarl, J. Alloy Comp. 515, 108 (2012).

[5] M. Poková, M. Cieslar, M. Slámová, Int. J. Mater. Res. 100, 391 (2009).

[6] M. Poková, M. Cieslar, J. Lacaze, Acta Phys. Pol. A 122, 625 (2012).

[7] M. Cieslar, M. Slámová, M. Hájek, J. Veselý, Mater. Sci. Forum 567-568, 325 (2008).

[8] Y. Birol, Scr. Mater. 59, 611 (2008).
[9] M. Vronka, M. Karlik, Key Eng. Mater. 606, 19 (2014).

[10] M. Poková, M. Cieslar, J. Lacaze, Manufact. Technol. 13, 212 (2012).

[11] M. Vlach, I. Stulíková, B. Smola, T. Kekule, H. Kudrnová, S. Daniš, R. Gemma, V. Očenášek, J. Málek, D. Tanprayoon, V. Neubert, Mater. Charact. 86, 59 (2013).

[12] M. Slámová, V. Očenášek, V.V. Voort, Mater. Charact. 52, 165 (2004).

[13] H. Weiland, S. Cheong, Mater. Sci. Forum 558-559, 383 (2007).

[14] Z. Jia, G. Hu, B. Forbord, J.K. Solberg, Mater. Sci. Eng. A 444, 284 (2007).

[15] M. Poková, M. Cieslar, Mater. Sci. Eng. IOP Conf. Series 63, 012086 (2014).

[16] M. Poková, M. Cieslar, J. Lacaze, in: Metal 2012 Conf. Proc., Tanger, spol. s r. o., Brno 2012, p. 1149.

[17] Y. Iwahashi, Z. Horita, M. Nemoto, T.G. Langdon, Acta Mater. 46, 3317 (1997).

[18] M. Poková, M. Cieslar, Manufact. Technol. 14, 412 (2014).

[19] W.C. Liu, J.G. Morris, Metal Mater. Trans. A 36 , $2829(2005)$

[20] W.C. Liu, B. Radhakrishnan, Mater. Lett. 64, 1829 (2010).

[21] W.C. Liu, J. Li, H. Yuan, Q.X. Yang, Scr. Mater. 57, 833 (2007).

[22] K. Juany, Y. Li, K. Marthinsen, Mater. Sci. Forum 794-796, 1163 (2014).

[23] Y.S. Sato, M. Urata, H. Kokawa, K. Ikeda, Mater. Sci. Eng. A 354, 298 (2003).

[24] I. Sabirov, M.Y. Murashkin, R.Z. Valiev, Mater. Sci. Eng. A 560, 1 (2013). 